\title{
THE IMPORTANCE OF LANDSCAPE DIVERSITY IN SPATIAL PLANNING OF PROTECTED AREAS ON CASE STUDY ON THE NATIONAL PARK MAVROVO
}

DOI: http://dx.doi.org/10.18509/GBP.2017.11

UDC: 712:911.52(497.76-751.2)

\author{
Hristina Odzaklieska ${ }^{1}$ \\ Olgica Dimitrovska ${ }^{2}$ \\ Dushica Trpchevska ${ }^{1}$ \\ ${ }^{1}$ Spatial Planning Agency, Skopje, Macedonia \\ ${ }^{2}$ Institute of geography, Faculty of science, University "Ss. Cyril and Methodius", Macedonia
}

\begin{abstract}
National park Mavrovo is located in the north-west part of the Republic of Macedonia. The protected area, differ the other protected areas in the country by the huge number of residential areas, 38 villages in total, with 8494 inhabitants.

The planned socio-economic development in the protected area, as indirect instigator on the nature modification, undoubtedly will initiate changes in the landscape diversity. Those changes may create a new values or may become a serious threat to the landscape types present in the protected area. Rural landscapes are most exposed to change, as the interaction between the man and the nature is greatest. The diversity of the landscapes that we have in the protected areas today speaks out the way that man treated the nature in the past, as it will speaks out in the future about the way we treat the nature today.

This paper elaborates landscape types in the National Park Mavrovo, their role in the spatial planning approach and propose measures for landscape diversity protection in the upcoming period. The proposed measures don't tend to restrict the future development in the protected area, nor to bring back the activities which were present in the past. They tend to permit sustainable development in the protected area, by allowing activities, that will preserve origin values of the landscape and create a new forms of landscape values in the area. This approach, enables control on the activities that may have a negative influence on the landscape diversity in future.
\end{abstract}

Keywords: landscape diversity, spatial planning, cultural land

\section{INTRODUCTION}

\section{Landscape diversity in spatial planning}

The first formal use of the term "landscape" comes from the german geographer Otto Schulter in the late 1890's. He focused his attention on landscape as the subject matter of investigation regarding "Landschaft" as a unit in which perceptible phenomena (natural or human), having spatial significance, form a distinct association" (cited in Palka, 1995, p.65) [2]. The emphasis on landscape as a basis for geographic inquiry was subsequently adopted by French geographers and later by American geographers and British geographers [3].

According to the influence of anthropogenic factors, landscapes are classified as natural and cutural landscapes. The clasic deffinition for cultural landscape derives from a human geographer Carl O Sauer "The cultural landscape is fashioned from a natural landscape by a cultural group. Culture is the agent, the nature is the medium, the cultural landscape 
is the result" [1]. The landscapes wich have not been exposed to anthropogen ic influence in the past are included in the category of natural landscapes.

Although an intellectual awareness of the concept of rural landscapes evolved in the 20th century, rural landscape planning and management is a relatively new professional field of land use and site management.

Preservation of the rural landscapes and their value is linked to the survival of traditional cultural patterns that have left a mark on the morphology of the area. In the past, the population behaved far more carefully to the nature and natural resources creating a landscapes of high aesthetic values and great environmental importance, which allows to the current generations to understand the area in which a culture has existed over the years. Landscape values of the areas that are attributed by locals or tourist visitors leave a long lasting print on their life and their lasting effect reflects the manner in which they experienced the landscape [8].

The inclusion of the rural landscapes as an important factor in the spatial planning proces in the protected area, means understanding the complexity of the landscape and proposing new solutions for improvement or protection of the landscape which allows strengthening the sense of belonging to a territory, preserving it's identity and creating new tourist attractions in the future.

\section{Landscape diversity in NP Mavrovo}

The analysis of landscape types in NP Mavrovo indicates the presence of high landscape diversity in the framework of natural and anthropogenic components in the protected area. According to the anthropogenic activities in the past, the landscapes in the National Park are classified as natural, semi-natural and rural landscapes [4].

The landscapes wich in the past had not been exposed to anthropogenic influence are natural landscapes. Natural landscapes are located in the strictly protected zones of the park proclaimed with the Spatial Plan of Mavrovo in 1988, gorge areas by the river flows and the surrounding scenery and the coastal areas of Gorna Radika and Mala Reka and their influents.

Landscapes which in the past were exposed to human influence, but the presence of the anthropogenic factor had not caused changes in the processes of nature and landscape values of the area, or reduced the abundance of natural phenomena in the area are included in the category of semi-natural landscapes. The forest areas in Dolna Radika and hilly mountain pastures on Bistra and Shar Planina are semi-natural landscapes.

The areas in which man inhabited over the time have grown into rural landscapes. All settlements in the park with meadows and farmland around them represent the rural landscapes in the park. Rural landscapes testify for the existence of the man in the area in the past, it's activities, lifestyle, customs, beliefs and traditional practices, or in other words for the specific interaction between the man and nature.

\section{Zoning in NP Pavrovo}

There are three protection zones in the National Park Mavrovo:

- Zone of strict protection. It covers areas that are in good preserved or original state. This zone includes areas with high concentrations of species populations that are under strict protection. The zone of strict protection in National Park Mavrovo covers an area of 8390,5 ha. It represents $11,6 \%$ of the total area. According the actual legislation in this field on national level, in strict protection zones are allowed research activities, if they are not in contradiction with the primary objectives of area protection. In order to 
maintain the characteristics of the zone, the entity which manages the protected area shall provide constant monitoring. It is expected that by application of appropriate protection regime, the space within this zone will keep it's original state.

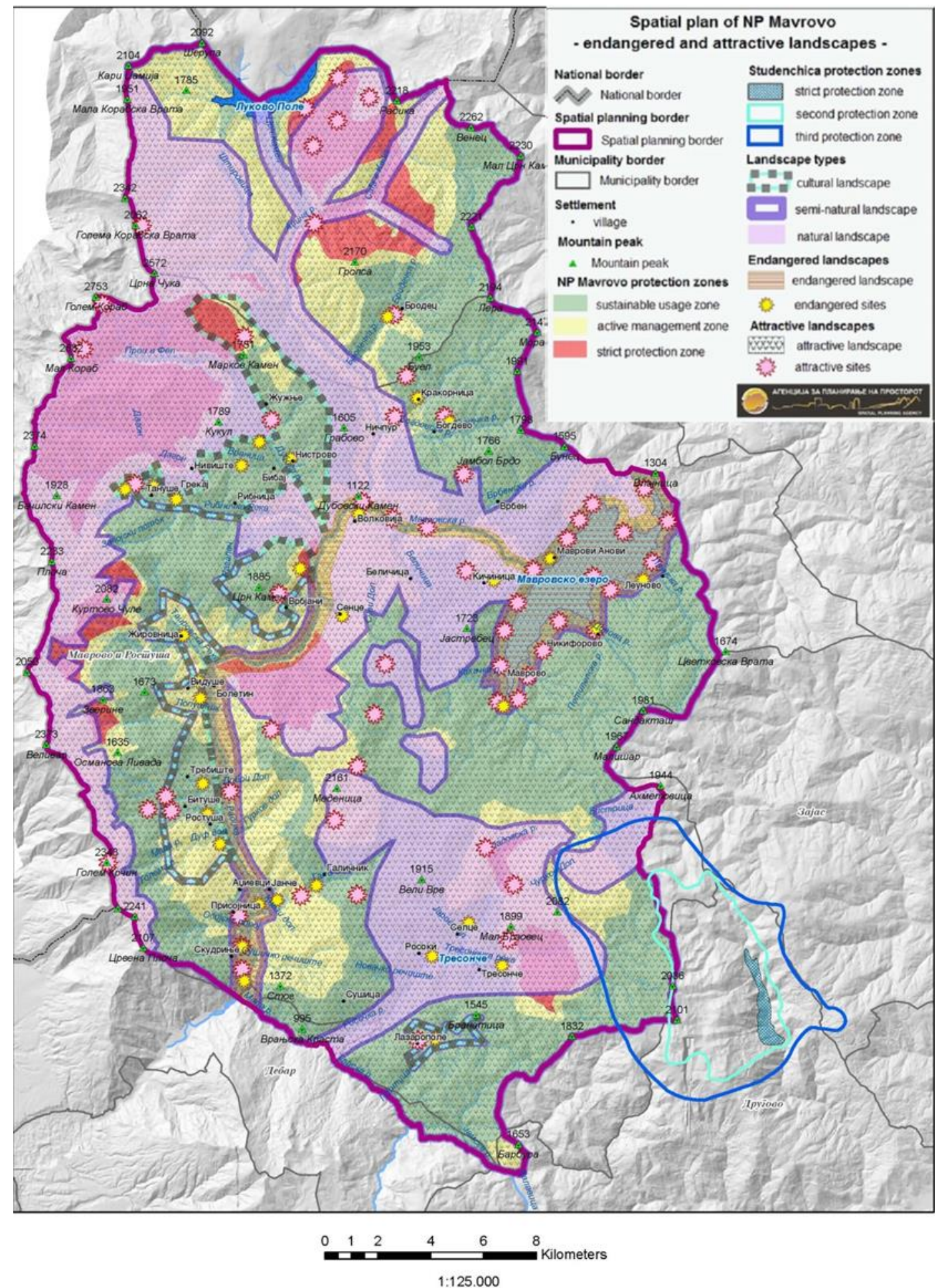

Zone of active management. It includes areas with significant components of biodiversity, however, populations of important species are less numerous, natural habitats are partly degraded. In this zone traditional management practices are still present. The zone of 
active management covers an area of 23248,1 ha, representing $32.1 \%$ of the total protected area. According the actual legislation in this field on national level, in the zone of active management are allowed management activities that are related to habitats and species manipulation and economical activities, as ecotourism or traditional extensive farming, that do not pose negative impact on the protected area. Appropriate management interventions for certain natural habitat types in the future, may include some areas from the zone of active manageent in the zone of strict protection.

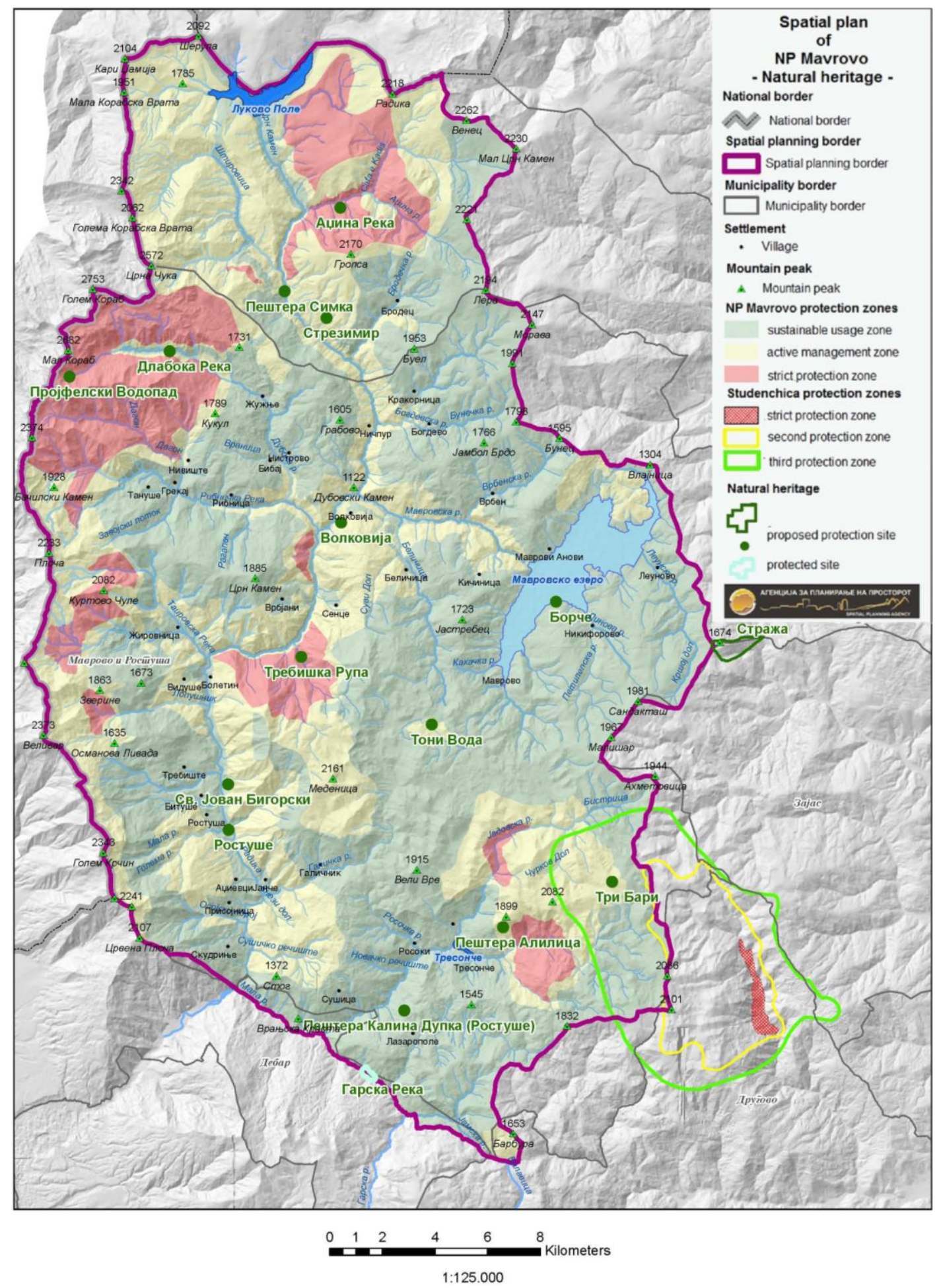


Zone of sustainable use. In this zone are located infrastructural facilities, objects of cultural heritage and types of forest plantations that are not typical for the protected area. It also includes all settlements situated in the Natinal Park, with the surrounding agricultural land. The zone od sustainable use does not have high level of protection. It covers an area of 40778,2 ha, representing 56,3\% of the total protected area. As a result of planned activities for sustainable use, which should be implemented in the next period, some areas from this zone may acquire characteristics of the zone of active management, which would initiate changes in terms of zoning in the protected area in future.

\section{ANALYSIS OF THE THREATS OVER THE LANDSCAPE DIVERSITY IN THE NP MAVROVO}

During the planning proces there had been identified potential threats on the landscape diversity in the NP Mavrovo: natural and anthropogenic threats.

All types of landscapes are exposed to natural threats cosed by the wind, soil erosion, climate changes and other natural factors. Constant threat to the landscape diversity in the park are the human activities present in the park over the years.Human activities that can pose serious consecuences on the landscapes in Mavrovo National Park are:

- $\quad$ Soil sealing (construction of weekend houses, with a new modern design that does not fit into the surrounding environment and cultural and architectural tradition of the park and building an infrastructure that does not fit into the surrounding environment);

- $\quad$ Tendency of development of massive tourism and unorganized visit of tourists in the park and

- $\quad$ Extraction of mineral resources.

\section{LANDSCAPE DIVERSITY PROTECTION MEASURES}

Landscape diversity in the National Park in the future, would be exposed on changes as a result of the planned socio-economic development wich should meet the needs of the people living in the National Park. Sustainable development and the management of the landscape diversity in the earliest stages of the planning process involves creation of planned measures to establish control over the activities that can have a negative impact on the landscape diversity in the future.

Planned measures for landscape protection should enable preservation and maintenance of the characteristic values of landscapes, wich result from it's natural configuration and / or the type of anthropogenic activities that are implemented or will be implemented in the planning period. Planning measures should not restrict the newly predicted activities in the are nor to tend to return to the activities that were prevalent long time ago, but to accept the proposed changes in a way that will ensure preservation of the specific characteristics of the areas in the park and their landscape values.

\section{Landscapes wich are not exposed to anthropogenic activities - Natural landscapes}

Based on the rich visual and aesthetic features, there are areas of special natural beauty or attraction and areas with special sceneries and landscape dominant in the park. Some of them are included in the zone of strict protection. In this zone anthropogenic activities are very limited so the threats from anthropogenic factor to the natural landscapes in the strict zone of the park are put under controll. Other natural landscapes placed in the zone of active management or zone of sustainable use, should be protected as enclaves in the 
national park with special protection regime, higher than the protection regime determined for the zone of protection.

\section{Landscapes exposed to anthropogenic activities - Semi-natural and rural landscapes}

The planned socio-economic development in the Natural Park in order to meet the needs of local population is indirect driving force as well as potential threat to the landscape diversity. Thus, preventive measures for landscape diversity protection should be made in the following sectors:

\section{1) Agriculture}

Agriculture management will have a considerable impact on the structure, composition and quality of the landscape that predominate in and around protected areas. The simplification and pollution of agro-ecosystems must be avoided or countered by adopting chemical-free and diversified agricultural systems to reverse the decline in species and habitat diversity in and around protected areas [7].

2) Forestry

Forests should develop naturally with minimum intervention in the forest fund generally through introduction of indigenous species.

3) Settlement development

Housing development at all levels is of great importance for the coherence and quality of the scenic ambience or the character and form of settlements. In the past, the position of the settlements in the park was linked to the environment and natural features, depending on the topography of the area and access to water. The settlements are located mainly in the forest areas. In Gorna Radika, they are located on the border between forests and alpine pastures. In Dolna Radika settlements are located in the lower forest belt, closer to the river terraces. Meadows, orchards and gardens are located besides the settlements. This distribution of the settlements gives the appearance of fine mosaic interlinkage of natural and rural landscapes, giving a unique and special feature of the Mavrovo National Park.

The settlements have a characteristic, often traditional architecture of buildings for housing. Olthough, there are several new buildings for housing that disrupt the traditional character because of the modern urban design that does not fit into the surrounding environment. A particular challenge in modern planning of settlements is the design of the planned contents in the park in harmony with nature, and pre-existing traditional values of the area. So, in the planning period, the development of settlements or construction of new buildings for housing should be placed on less prominent locations due to reduced impact on the surrounding landscape.

4) Construction

Planned infrastructure facilities should fit in the surrounding landscape, outside of an areas with high environmental values.

\section{Energetic infrastructure}

The position and alignment of the new housing and their windows in relation to exposure to sun direction and prevailing winds can be very important in relation to cooling. Designs to maximise natural light without causing increased temperature via direct sunlight will contribute to low energy usage. There are many lessons to be learnt from old buildings, constructed before modern electric cooling and lighting were available (and links here to heritage registers, the need to conserve the built heritage and to design new buildings to fit their context). A thatch roof can also provide added insulation and natural cooling [6]. 
Considering that in the zone of active management in the past have been built power infrastructure facilities, which are still in operation, in the planning period should be allowed their reconstruction and maintenance, with minor influence on the landscape diversity. The new energetic infrastructure should be planned in the zone of sustainable development and it should be generally based on renewable resources.

Integration of road infrastructure

Routes of new roads in the rural areas should follow the natural line in the space, allowing visual experience of the local character of the landscape on both sides of the road. While designing the road it is necessary to explore the landscape types through which the route passes along the way in order to make efforts to increase the expression of the characteristic relief forms and if it is possible to restore the surrounding degraded areas in order to maintain the character of landscape along the route of the road. The surrounding areas of the route should be carried out with species which visually integrate the scenic surroundings and have a protective role of the existing vegetation by increased noise levels and increased concentrations of harmful substances, which are expected to generate increased intensity of traffic especially in the tourist season. The surrounding vegetation should not follow the route of the road. It should match with the existing vegetation on the both sides of the road [7].

Exploatation of mineral resources

Mining of mineral resources will undoubtedly cause changes in the visual experience of the landscape. Changes may be short term, if there is plenty of land for restoration of the landscape and its return to its original form, or long-lasting, causing irreversible transformation of the same. The loss of the specific characteristics of the area can give a brand new character of the landscape. According to the IRMA (Initiative for responsible mining assurance) Standards for Responsible Mining, these activities aro not alowed in the National parks ${ }^{1}$.

5) Development of tourism:

Less populated areas in the National Park Mavrovo are not sufficiently activated as tourist destinations and have huge untapped potential, because of the exceptional landscape values and landscape dominants in the immediate surroundings. In the planning period these areas should be activated and sustainablly managed through creation of a network of tourist destinations. In this way the torism offer in the park will be completed and diversyfied.

Creating educational training programs for the local population about the values of the cultural heritage, as a motive for linking population with the local environment, but also highlighting the potentials of space for economic benefit to the local population (training of the locals about the history, geography and nature of the area and their inclusion as an accompaniment or engaging as tour guides at introducing visitors to the park with it's values, traditional customs, regional specialities and crafts typical of the area).

\section{CONCLUSION}

Since the environmental preservation has dominant role in protected areas, landscape diversity management in the modern spatial planning process should have priority place. In general, the primary aim of protecting the values of the National Park Mavrovo and the planned socio-economic development of the area supported by the application of

\footnotetext{
${ }^{1}$ http://www.responsiblemining.net/irma-standard/irma-standard-draft-v2.0
} 
Sandford principle ${ }^{2}$ and Silkin Test ${ }^{3}$ sets a clear framework for the limits within which the future development should be driven in the boundaries of the protected area. According Sendford principle, in terms of conflict, priority should be given to the primary aim of protecting the park and its values. On the other hand, all development projects in the future which are expected to be realized within the National Park, should be subject to Silkin test. This test determines whether the realization of the planned development project is absolutely necessary and is of national importance and is there an alternative for getting the service of the development project outside of the borders of the protected area.

Planned measures for landscape diversity conservation should enable preservation of the landscapes in wich anthropogenic factor has been major threath over the years and minimize human influence on the values in the protected area.

\section{REFERENCES}

[1] Sauer, Carl, 1925. The Morphology of Landscape, University of California Publications in Geography, vol. 2, n o 2, pp19-53

[2] Palka, E.J. (1995): Coming to grips with the concept of landscape. Landscape Journal 14, 6373.

[3] Dal Prasad Pul (2004): Rural Landscape Change: Landscape Practices, Values and Meanings The Case of Jagatpur VDC, Chitwan Nepal, Norwegian University of Science and Technology (NTNU)

[4] HadziPecova S. (2010): Predelite vo Nacionalniot Park Mavrovo, Study made in the framework of the project "Zastita na zivotnata sredina, ekonomski razvoj i promocija na odrzliv eko-turizam vo Nacionalniot Park Mavrovo", Skopje

[5] Controlling the environmental effects of surface mineral workings (1996), ISSN 0141-514X, ISBN 074805652 1, The Scottish Office Development Department

[6] Guidelines for Activities in Protected Areas, 2013, Compiled by UK Overseas Territories Conservation Forum for the EU-supported project on Management of Protected Areas to Support Sustainable Economies (MPASSE)

[7] Scialabba N. \& Williamson D. (2004): The scope of organic agriculture, sustainable forest management and ecoforestry in protected area management. Environment and natural resources, Working paper No. 18, Food and agriculture organization of the United Nations, Rome, 2004

[8] Council of Europe (2006): Landscape and sustainable development, Challenges of the European Landscape Convention, ISBN-10: 92-871-5988-2, ISBN-13: 978-92-871-5989-2, Council of Europe, Strasbourg

\footnotetext{
${ }^{2}$ http://www.saynotopig.co.uk/Summary/Sandford-Principle.html

${ }^{3} \mathrm{http}$ //www.cotswoldsaonb.org.uk/userfiles/file/meetings-2013/board-meetings/5-dec-2013/8-apx-bnick-boles-meeting.pdf
} 